\title{
WORKING RIVERS
}

HEATHER GOODALL

University of Technology Sydney

\section{Abstract}

For many people, rivers are understood and expected to fulfil functions-to 'work' in some sense. The word 'work' itself is loaded with emotion and value judgement, but beyond this, it is often the case that the work in which people are employed shapes the way they see and value rivers. This paper considers five different ways in which different groups of people in rural New South Wales, eastern Australia, might identify the work that rivers do, including irrigation, carrying nutrients, nurturing fish, offering livelihoods for humans and expressing cultural values. In considering this work, this article draws on the views of irrigators, pastoralists, fishers, scientists and Aboriginal people-who might themselves be involved as irrigators, pastoralists or scientists, and certainly as fishers. This article explores the ways in which employment-the work these people might do-has given them particular ways to see the river. For some, their own employment has narrowed the aspects of rivers that they value, leading them to disregard much about the flow of water across the landscape. For others, the mobility or economic marginality of their work has allowed them to see rivers in a far wider context than has been the case for others.

\section{'I always feel a river should work for its living!'}

In Leona Skelton's studies about the deindustrialised River Tyne in the UK, she reveals the ambivalence that riverside residents feel towards the cleaned-up river, which has resulted from the loss of industry. This quote was the rueful confession of one woman who has lived near the Tyne all her life and suffered from the closure of its factories. ${ }^{1}$

This paper explores the idea of work in relation to rivers, which have been romanticised in many literary traditions as sources of repose and tranquillity. The word itself is ambivalent-does 'work' mean to function 'well' (in itself a word with many meanings)? Or does it mean to be productive? Keeping this ambivalence in mind, this paper will discuss the separate, but related, questions that arise from Skelton's important study. How might a river work? And how do working lives shape the way we know a place, a river, an environment?

1 Leona J. Skelton, Tyne after Tyne: An Environmental History of a River's Battle for Survival, 1529-2015 (Winwick, Cambs: White Horse Press, 2017). 
Rather than the post-industrial river of Skelton's research, my focal area is the complex inland freshwater system of south-eastern Australia, which includes the Murray and the Darling Rivers, along with their many tributaries. The system rises, as the accompanying map shows, in two places: the Darling from Queensland in the north and the Murray from the Snowy Mountains in the south-east. These two main rivers meet near the border of New South Wales, Victoria and South Australia, and then arc to the south to finally reach the sea at Goolwa, south of Adelaide.

Although I will discuss the overall system, including the Murray, the paper will concentrate most on the area of my work with people and events in the area known as the upper Darling. This is a complex floodplain-water flows from the east but only coalesces into the main stream known as the Darling River at Bourke, from which even then it is flanked by small contributing creeks, parallel billabongs and ephemeral lagoons. In its upper stretches, its many tributaries, including the Macintyre running from the north-east and the Macquarie and Namoi running from the south, flow into the Barwon River, which passes through Brewarrina and, only then, once joined by the system known as the Culgoa-Balonne and finally the Paroo, all flowing from the north, does it finally become the Darling. In this upper Darling area too, each of these tributaries is also flanked by ephemeral lagoons and billabongs.

I have been fortunate in being able to explore the impacts on the rivers and the way people have understood these changes with extraordinary co-researchers in two projects. In the Black Soil Country Project, I was able to work with the historian and radio producer Damian Lucas to look at culture, industry and memory on the upper Darling. ${ }^{2}$ In Talking Fish, I worked with historian Jodi Frawley and the aquatic ecologist Scott Nichol to trace how fishing people understood the river across the whole Murray-Darling system. ${ }^{3}$

For millennia, the complex streams of the upper Darling have been the core of the country of the Kamilaraay, Yuwalaraay, Murawarri, Wailwan and Ngiyampaa peoples, who continue to live along the waterways as they arc from the north-east

\footnotetext{
2 Heather Goodall, 'Gender, race and rivers: women and water in northwestern New South Wales', in Fluid Bonds: Views on gender and water, ed. Kuntala Lahiri-Dutt (Kolkata: Stree Books, 2006), 287-304; Heather Goodall, “"The River Runs Backward”, in Words for Country: Landscape and Language in Australia, ed. Tim Bonyhady and Tom Griffiths (Sydney: UNSW Press, 2002), 30-51; Heather Goodall, "'Speaking what our mothers want us to say": Aboriginal Women, Land and the Western Women's Council, 1980-1985', in Words and Silences: Aboriginal Women, Politics and Land, ed. Peggy Brock (Sydney: Allen \& Unwin, 2001), 18-55.

3 Jodi Frawley and Heather Goodall, 'Transforming Saltbush: science, mobility and metaphor in the remaking of Intercolonial worlds', Conservation and Society 11, no. 2 (2013): 176-86, doi.org/10.4103/0972-4923.115723; Jodi Frawley, Scott Nichols, Heather Goodall and Liz Baker, Talking Fish: Making Connections with the Rivers of the Murray-Darling Basin (Canberra: Murray Darling Basin Authority, 2012), www.dpi.nsw.gov.au/_data/assets/ pdf_file/0015/442140/FINAL-Talking-Fish-booklet-compilation-Jan-2013_for-web.pdf, accessed 30 October 2017.
} 
around to head south-west to the Murray River. ${ }^{4}$ Since the 1850 s, this floodplain has also been central to the grazing industry, which formed the backbone of the settler Australian economy until the mid-twentieth century. ${ }^{5}$ More recently still, since the Second World War, many of the larger rivers, including the Murray, the Murrumbidgee and, since the 1960s, the Darling, have been sources of water for irrigated agriculture, including cotton, watermelon, citrus and other crops. ${ }^{6}$ Over these decades, both the pastoral and the agricultural industries have called for weirs and dams to conserve water in dry years and to hold back the flows in times of flood. While there are few large dams on the north-western rivers, almost all of the tributaries of the Darling have been obstructed and slowed down by the addition of weirs and causeways. Only the most western-the Paroo River-has remained 'unregulated' by dams or weirs, although periodically calls are raised that it, too, should be controlled.

This diverse area can all be called a river 'system' because the waters are connected. The Australian climate is characteristically variable — although often considered arid, many inland areas are in some years subject to deluges and widespread flooding. The main rivers have altered their beds during such floods, when the lagoons and billabongs link to the main streams as well, so that while some years the rivers seem to be single and discrete channels, in other years they are widely spreading, slowmoving lakes. In the aftermath of the floods, waters lie in many areas across the plains for months. The resulting silt from flooding, the 'black soil', is fertile and retains water, making it difficult to traverse in even the lightest rain but producing abundant fodder at times when the higher sandy and stony ground, the 'red soil', has very different and, for stock, often inedible, plants.

The river water and the diverse plant life on both types of soil have ensured productive uses of this floodplain by many economies, from Indigenous harvesting to the more recent cropping. So this system has been the site of many people's working lives. As this paper will discuss, the goals and technologies of that work have shaped what people could know about the river, what they noticed and how they understood it. Their cultural knowledge, their stories and expectations all fostered ways to understand the river, which were sometimes shared between these peoples and sometimes held separately. All these have contributed to different ways of thinking about whether the river is 'working' - that is, whether or not it is functioning 'well'.

4 Heather Goodall, Invasion to Embassy: Land in Aboriginal politics, 1770-1972 (St Leonards: Allen \& Unwin, 1996).

5 D. N. Jeans, An historical geography of New South Wales to 1901 (Sydney: Reed Education, 1972).

6 Siobhan McHugh, Cottoning On: Stories of Australian Cotton Growing (Sydney: Hale and Iremonger, 1996); Marilyn Lake, The limits of hope: Soldier settlement in Victoria, 1915-38 (Melbourne: Oxford University Press, 1987).

7 Some of these major flood events have been charted by Emily O'Gorman in Flood Country: An Environmental History of the Murray-Darling Basin (Collingwood: CSIRO Publishing, 2012). 
If the rivers in this inland system do work-in the sense of offering a basic function for all the living beings related to it-they have to carry fresh water. This need is shared not only by the humans along the river system's path, but also by the plants it waters and by the endemic native animals or exotic stock that drink from its waters, as well as by the living beings within those waters and those outside but dependent on it, like birds and insects. Often no rain falls in the regions through which these rivers run, so the river acts as an important carrier of fresh water from more distant places upstream where rain falls. Conversely, if too much rain falls-as it often does in the variable Australian weather pattern-the rivers may carry too much fresh water and may flood well beyond their banks. Is this too regarded as working? Beyond the call for a manageable amount of fresh water, however, the expectations of how rivers might work are varied greatly by the working lives of the people who experience these rivers. I will proceed to move from the most recently established work to the longest-established—and continuing — way to understand the river.

\section{Irrigation rivers}

The most recent land users in the region are the irrigators, who need water to work in a particular way as it flows through the complex technology they use for the agriculture they practice. This is the topic of heated debate in Australia at the moment-again - in the long and bitter conflict over clawing back an allocation of water for 'environmental flows'. ${ }^{8}$ Irrigators do try to harvest surface water, but the most common source of irrigation for intensive horticulture like cotton and paddy rice is pumped river water. The pumps are large and common along the increasing lengths of the rivers along which intensive agriculture is practised, and in these situations the technology determines the ways in which the river is required to function. ${ }^{9}$ The goal of pumping is to deliver uncontaminated, clear, fresh water to crops. So pump technology filters water as it enters the mechanism to exclude much of the river contents, like vegetation, fish and suspended biota. These are 'bodies' that block the pumps and impede the pumping process, and so they need to be excluded or discarded.

\footnotetext{
8 Anna Vidot and Brett Worthington, 'Murray-Darling Basin Authority recommends reducing water buybacks in northern communities', ABC News, 22 November 2016, www.abc.net.au/news/2016-11-22/ murray-darling-basin-northern-communities/8042496, accessed 30 October 2017. In mid-2017, the debate ignited yet again, as the Wentworth Group of Concerned Scientists released their 2017 review of the Murray-Darling Plan and argued that the goals of the plan for the river, which aim to restore and conserve its ecological health, are not being met: wentworthgroup.org/2017/06/fiveactionstodelivermdbplan/2017. Already there have been attacks on the Wentworth Group, and the Murray-Darling Basin Authority has leapt to the defence of its planning process, insisting it is meeting its ecological as well as its economic goals. (Gregg Borschmann and Sara Phillips, 'Climate review promised after dispute with top water scientists', RN Breakfast, 22 June 2015, www.abc.net.au/radionational/programs/breakfast/climate-review-promised-after-dispute-with-topwater-scientists/6547394, accessed 30 October 2017 .

9 Goodall, 'The River Runs Backwards'.
} 
Floods_ - or excess water-also pose a problem for the carefully regulated delivery of water to irrigated agriculture, which seeks a predictable and reliable flow of water to maintain a growing schedule. This has posed a major challenge for irrigators on the Murray-Darling system, which, as discussed above, is characterised by variable flows. Irrigation has been the most recent addition to the long-established settler pressure to regulate the rivers' flows with dams and weirs, ensuring that it is delivered at a rate that maximises the capacity of the rivers to deliver the measured amount of water needed. The river has now become much slower over the same time as it has become much more nutrient-rich, with pastoral animal waste and township human sewage deposited in the river, intentionally or accidentally, in addition to the fertilisers used in both pastoralism and horticulture. So, in a dry year, the dams and weirs slow the river waters' flow even further, which in the summer leads to unwanted results, like the massive blue-green algal bloom that turned 1,000 km of the Darling River bright blue in 1991, making it toxic to humans and animals. This is 'collateral damage' - an unfortunate by-product — of the heavy use of dams and weirs, which limit the variability and speed of the nutrient-enriched rivers' flow in hot weather. ${ }^{10}$

The industries dependent on irrigation-cotton and intensive horticulture-have been vocal in asserting the importance of irrigation to the Australian economy and the world food and commodity supply. As concern has grown that the work of irrigation is damaging to the other types of work the river might do, it has been these well-organised and well-funded lobby groups that have won out in the planning for 'sustainability' through the return of 'environmental flows'. ${ }^{11}$ Yet there are individual irrigators who have seen more than their profitability to be at stake and, for them, the other types of work that rivers might do-the social and the cultural work-are also important. ${ }^{12}$

\section{Fertile rivers}

For longer-term users, like the graziers and those agriculturalists who do not rely on irrigation, it is the contents of the river water, not just the volumes they get, that are essential components of how the rivers work. The very things that cause problems if they are introduced into the irrigation machinery - the fish, weeds, silt and biota-are essential for these other users. It is this rich mineral and organic

10 Murray-Darling Basin Authority, 'How blue-green algae blooms are handled', www.mdba.gov.au/managingwater/water-quality/how-blue-green-algae-blooms-are-handled, accessed 30 October 2017.

11 Murray-Darling Basin Authority, 'Water for the environment', www.mdba.gov.au/managing-water/ environmental-water, accessed 30 October 2017; Murray-Darling Basin Authority, 'Basin Plan Amendments: Northern Basin Review', www.mdba.gov.au/sites/default/files/pubs/773-BP-amendments-nbr-snapshot.pdf, accessed 30 October 2017.

12 Cameron Muir, 'Feeding the World', Griffith Review 27 (2010): griffithreview.com/articles/feeding-the-world. 
matter that increases the fertility of the land after flood waters have spread across it. This is the 'blacksoil': it is the organic and mineral-rich silt deposit left on the land as flood waters recede. This silt is essential for dryland cropping and for the growth of stock fodder. Ironically, it is also essential for the irrigated cotton-which is only grown on the black soil due in part to its higher water retention compared to the 'red' sandy ridges in between. The 'empty' water that flows through the pumps is not enough to enrich the soil in the way that the silt and biota residue does.

These flooding events might be troublesome for all land users, leading to 'waterlogging' and interrupted growing cycles; however, as well as ultimately enabling greater productivity on land, these flooding waters also do work that has a social dimension because they generate stories. All long-term residents have stories about these floods. Indeed, the flood is there constantly in the imagination of the people talking about this landscape between the rivers, often referred to as 'the flooded country' even when it has long been dry. But then there are all the stories about the challenges of flood times when the black soil is wet, when the roads on it turn into sucking bogs that can cause cars to sink to the axles and - so legend has itconsume whole bullock trains, bullocks and all! $!^{13}$ What poses problems here are the obstructions to the movements of waters in flood-raised roads, excavated tanks or dams with banks around them, or buildings on mounds—all obstruct and redirect the flow of flood waters, confusing people who have grown used to floods moving in predictable ways. It is a measure that the river is working well if it generates such stories because the flood is having effects, making the changes to the landscape with deposits and waterlogging, which will ultimately have the effect of making the land more fertile.

\section{Fished rivers}

For all of those people already discussed-irrigator, grazier and worker, including Aboriginal people in each of these categories - these are fished rivers. An essential marker of the river's capacity to work in any sense is that it be a reliable source of fish, whether it be for subsistence, for social obligations, for profit or for recreation. To meet this demand, the waters of the rivers have to be a comfortable and safe home for fish. This means, for example, that river water has to be the right temperature for breeding, which poses a problem where weirs and dams release water from their depths that is much colder than that which flows along the riverbeds. The

13 Poems like Banjo Paterson's 'Hell, Hay and Booligal' and the iconic 1899 painting by George Lambert, Across the Black Soil Plains, all depict the difficulties of moving cargo by bullock wagon across the floodplain. The legends of bullock drays consumed in black soil bogs are word-of-mouth yarns that I have heard over the years along the upper Darling. 
temperature affects the many forms of biota in the river waters, which are needed as food for fish. With many different species of fish, there need to be many different varieties of living things for them to eat.

Then the walls of the weirs and dams are a barrier to fish swimming upstream to breed or feed. The 'fish ladders' installed to overcome these barriers have not always been successful, as the residents at Brewarrina have come to know over many years. ${ }^{14}$ The very things that have been necessary for the work of rivers used for irrigation, like weirs and dams, therefore undermine the process of fish reproduction, which is necessary for fishing. But there are further problems caused by the stock of commercial flocks of sheep or herds of cattle, whose hard hooves break up the banks, leading to the destruction of bank vegetation as well as to puddles of standing water and unbalanced breeding of some species such as mosquitoes.

Yet there are benefits, too. Such accidental puddles and pools_-along with the long drains called 'bore drains' that spread water out from artificial reservoirs (ground tanks) or from artesian (ground water) bores for stock or crop irrigation-have extended the range of a host of other creatures that are not usually counted by settler fishing people as part of the river's harvest. For Aboriginal people, however, aquatic animals like mussels and yabbies are a crucial element of the river's life. They have been gathered and eaten for generations - often by children while their older relations fished-and they have been an important learning site as well as a barometer of water-quality change. Along with the reeds in the water and along the bank, which are gathered for weaving, and within which young fish and other creatures shelter, the yabbies, mussels and reeds form the rich edible and valuable things that a day on the riverbank yields. These living things are not 'fished' but they are as much a part of the continuing Aboriginal economy and lifestyle as are the fish themselves.

Some exotic species, like trout, have been introduced into the river system deliberately because they offered good fishing opportunities. These species have been welcomed by many fishers, Aboriginal and non-Aboriginal, who enjoyed them both as food and sport. Other exotic species, however, have expanded uncontrollably far beyond any initial purposes for their introduction. The most invasive and environmentally damaging of these in the Murray-Darling system are believed to have been the European carp. Their bottom-feeding habits and rapid breeding are blamed for damaging underwater habitats and undermining the numbers of highly valued endemic native species such as Murray Cod.

14 Heather Goodall, 'Crisis on the Darling: understanding conflict between Aboriginal people and ecologists', Current Conservation 8, no. 3 (2014): 12-17. 
Despite millions of people around the world regarding carp as an edible species, most people along the inland rivers do not. Instead, carp are despised as smelly, full of bones and foul-tasting, and are accused of causing most of the rivers' ills. A more considered view is that the conditions of the river have been dramatically altered by regulation - the construction of dams and weirs-slowing the rate of water flows and lowering the temperature of the water. This has made the overall habitat less favourable to the highly adapted endemic species and more favourable to the European carp, which has consequently risen in numbers. ${ }^{15}$ This explanation is disregarded by most river residents, Aboriginal and non-Aboriginal, who take part gleefully in competitive 'carp musters', organised by local groups interested in improving river quality and restoring native fish numbers. The winner of the 'muster' is the fisher who catches and kills more of the hated fish than anyone else.

The fishing for all sorts of fish-even carp—has created a rich legacy of stories, which is without question one of the ways fished rivers work well: they generate social exchanges in many conversations both before and after the fishing takes place. But just as important, fished rivers enable social interactions in practice, from river bank barbecues and social gatherings fuelled by fish and competition-friendly or otherwise - to the fulfilment of obligations of all sorts to share the catch around.

Not only are there stories about fish and fishing, but there are the stories told while fishing - a pastime that involves long quiet hours of sitting on river banks or in small boats. In those times, many children recall learning from the older people they were with. This is a particularly common memory among Aboriginal people, who were often cared for during the day by grannies or grandfathers, aunties and uncles, while their parents were working on the pastoral runs around the river. The stories these people remember hearing were not only about fishing catches but about the big cycles of philosophy about river meanings in Aboriginal cultures, including the legendary creatures still living deep in the river bend holes and the epic stories of the creation of the rivers. These legendary creatures - often with human qualities were also often imagined as fish or crocodiles or water snakes-powerful embodied forms of creative energy that carried keys to the philosophies of whole cultures.

At the same time as these stories of law and philosophy were being passed on, Aboriginal people recall that they were being told the stories about what it was like during the period of invasion and colonisation. Many conflicts and massacres occurred on water courses either because that was where Aboriginal people might be camped or where they would run to seek shelter (like the well-documented killings at Hospital Creek near Brewarrina and Myall Creek near Bingarra). ${ }^{16}$ Stories would be told too about more recent events: there have been long decades when

15 Paul Sinclair, The Murray: A River and Its People (Carlton: Melbourne University Press, 2002).

16 A wonderful example of documentation of Aboriginal people's recollections of these riverbank experiences is the 2013 Western Heritage Group compilation, Yamakarra! Liza Kennedy and the Keewong Mob (Wilcannia: Western Heritage Group, 2013). 
people were camped on riverbanks because town housing and water supplies were segregated. This meant that schooling - under constant threat of child removalinvolved many trips up and down the river bank for water for washing bodies, hair and clothes, as well as for cooking and drinking. ${ }^{17}$

Stories of riverbanks for Aboriginal communities were often a very different type of story that that told by non-Aboriginal people. Yet, for non-Aboriginal people too, there are endless river and fishing stories_-about large social events and about secret assignations — stories all passed on, or at least hinted about, while fishing. This work of the river is largely invisible and seldom recognised. Riverbanks, river waters and fishing have played a creative social role far beyond that of subsistence, commerce or competitive recreation. They have been the sites of intergenerational transmissions of histories and cultures as well as the glue that has bound people together and, at the same time, has bound people to places.

\section{Networked and nurturing rivers}

Yet another type of work that rivers have done can only be recognised if we can see the rivers as complex and multi-channelled. Many of the people whose stories have been referred to in earlier sections have been closely involved with short reaches of the river-they might know one area intimately, but they have far less detailed knowledge or personal, embodied experience of other places.

Some people have travelled more widely across the regions within the system, sometimes because of their jobs or sometimes just because of their curiosity about fishing. Their stories are less often told because their mobility seems to detract from their 'place attachment', when 'place' is considered to be a relatively small and bounded area. Yet, such mobile people offer perspectives on how rivers work because they have experienced not just one channel of this river system but many channels and waterways - rising in different places, having different characteristics, yet all eventually flowing into the same main streams. Those people who have travelled across the many different types of water flows can offer thoughts about how the whole system has changed. Their observations can, for example, highlight the importance of habitat for fish-the wider picture in which fish may swim, breed and feed in different parts of the system. So their observations may sometimes signal big changes in the health of the river system as a whole.

Here are two examples of people who were able to learn about many different types of channels in the system. They come from quite different backgrounds and occupations and travelled in different regions. But they share the experience of 
thinking of many different parts of the system at once. One is John O. Langtry, a biologist who surveyed fish and other riverine species along the Murray and lower Darling rivers in 1949 and 1950. The other are an Aboriginal couple, Joe and Pearl Trindall, Kamilaraay people who live on the Namoi River today but who worked as drovers during the 1950s and 1960s, raising their family as they travelled the stock routes between rivers and bores across the upper Darling region. ${ }^{18}$

Langtry was a young biologist when he joined the first team recruited by the Victorian Fisheries and Game Department to undertake a systematic survey of fish along the Murray and Murrumbidgee (both fished by commercial and recreational fishers), as well as the lower Darling, although it was officially closed to commercial fishing at the time. Langtry had grown up in the city but enjoyed many family fishing holidays on inland rivers with his parents and uncles. In 1949, the research team to which he was attached ranged widely across the region, camping out, up before dawn to start fishing, sampling and talking to everyone they could find to learn what they knew about the fish in the rivers. Langtry remembers spending time with commercial fishers and with graziers and stockmen on properties who fished for pleasure, with fishing inspectors and with poachers - in fact, with anyone who had observations and information about fish and fishing.

His time camping out was not only enjoyable, but it was also an opportunity for observing other creatures on the river, some of them dependent on the fish, like the birds he watched congregating on the Menindee Lakes, or living in the river with the fish, like mussels, or who made a living themselves from the water and the land, like the water rats and snakes he watched in the Murrumbidgee. Langtry's experience was a common one-he was concerned mainly with fish, but in the process he learned a great deal about the many other living creatures in the river and the ways they were related to each other and to the water's flow. Overall, he felt that fish offered a good indicator of the river's health, although not necessarily the most sensitive indicator. Most of all, he felt that the fish had a social importance in drawing people to the river for their enjoyment and observation. ${ }^{19}$

His memories are striking in their recognition of the flow of water across the landscape. He spoke, for example, about the benefits offered by flooding, which hydrated the soil, drawing water deep into the soil structure where it would be slowly released and be productive. This overview led him to see a particular importance for anabranches, billabongs and tributaries — the 'lacework' ${ }^{20}$ — of waterways that make up this complex Murray-Darling system. As a biologist, he was keenly aware of the different environments that anabranches offered, for example, for breeding small

18 Both interviews were conducted early in the Talking Fish project. While the Trindall's story was addressed in one of the community books produced by the project on the Namoi River, the interview with J. O. Langtry has not yet been fully explored.

19 J. O. Langtry, interview by Heather Goodall and Jodi Frawley, 16 August 2010.

20 J. O. Langtry, interview. 
native fish, which were sheltered there from the rapid flow of the main channels. Yet, he was also concerned that such quieter waters might inappropriately provide breeding grounds for alien fish, at the expense of natives. ${ }^{21}$ He saw this 'lacework' as a significant part of the whole system, rather than focusing on the main rivers that are often the ones visible on the map, as he explained:

The Murray River, and hence its fisheries, were dominated really, for breeding grounds ... around those anabranch areas. The anabranches come off-they spill over the bank in high water and trickle off for miles and miles and miles, hundreds of miles and come back to the Murray. Or they just go off and join another river. ... So there was a complex web of water base, which meant that very high flows dissipated but, more importantly, they went in [to the soil]. There was this huge cleansing. And a huge breeding area. All the [birds and land animals] came round, there was ample room everywhere. And another benefit was the landscape of the Riverina was pretty well saturated.

If I hadn't been in the Fisheries [Department], I wouldn't have seen the significance of the anabranch distributary systems. And they turned out to be critical to understanding those rivers. Those two huge river systems. ${ }^{22}$

In a parallel to his recognition that the rivers needed to be understood in their entirety, as a 'lacework' and a 'complex web', Langtry also believed he learnt most from local knowledge when he talked to all types of fishing people. Anyone who fished-whether they did it as a hobby, for a living or as a poacher-was for him a source of knowledge about the river and how it was changing. In particular, he stressed that, as a scientist, he learned most about fish because he did the fishing. As he explained: 'So, the thing about it is not just to go and LOOK at the river, it's to go and WORK it. To handle it, to DO it! It's the only way'. ${ }^{23}$

Pearl and Joe Trindall had a very different experience of the river system. They worked hard as drovers, concentrating on rivers as watering points for the cattle and sheep they were herding as well as offering themselves good fishing while they watered the stock. Like Langtry, they met many people along the stock routes, most often working people, and especially fishers at the campsites, people like themselves who were fishing for food while they worked as fencers, stockmen, rabbiters and sometimes travelling showmen. The Trindalls' knowledge of fishing arose partly from their own childhoods. They had each been born on different rivers within the overall Darling system-Pearl on the MacIntyre and Joe on the Namoi-but both had grown up within Gamilaraay traditions. They had been taught about the epic battles that the ancestors had fought that had created the river channels, the deep holes where fish hid and the mysterious springs that released water deep into Boobera

21 P. L. Cadwallader, ed., J. O. Langtry's 1949-50 Murray River Investigations (Fisheries and Wildlife paper, 13) (Melbourne: Ministry of Conservation, Fisheries and Wildlife Division, 1977), 21.

22 J. O. Langtry, interview.

23 J. O. Langtry, interview. 
Lagoon near the MacIntyre or far away from the main river like Gaurigal Springs at Angledool near Goodooga. Joe remembered a childhood where 'everybody fished!'. His extended family would meet on the riverbank and fish all day, then cook the fresh catch wrapped in mud on a big fire.

As a young married couple in the 1940s, the Trindalls also learned to compare the rivers not by looking but working —although, unlike Langtry, their work consisted of judging the flow so they could water their stock, which at times might be as many as 15,000 head of cattle. But they also needed to fish to live themselves, and later to feed their children, so they were looking for good fishing and camping spots. They raised seven children as they travelled, droving across the rivers of the upper Darling. So they planned all their movements based on their knowledge of rivers- - how long it would take this mob of cattle or sheep to walk that distance; where the special spots were to water stock safely; how much water they might find at the end of the day's drove. 'The river was everything', Joe explained, 'Water was everything. ${ }^{24}$

Unlike Langtry, their awareness of water went even further than the anabranches and billabongs, although they talked a great deal about them. But as they moved to camp and water stock, they were aware too of all the bore drains and excavated ground tanks - the artificial watering points—which have added to the river system on the northern plains. These too have fish, as well as riverine creatures like yabbies that made important food sources for drovers as well as water for travelling stock. The Trindalls explained that the fish in the ground tanks, for example, had arrived in floods and been left when the river waters retreated. So their awareness was not only of the river channels but also of the floodplain —where the river periodically spread far out beyond even the anabranches and billabongs - and left a living memory on the watered landscape long after the flood event had passed. Their recognition of the Murray-Darling system as a floodplain — with water ebbing and flowing across its surface-may help us to understand the overall network as a system rather than a series of channels carved across a stable landscape. In fact, the whole landscape is shaped by water-whether or not the water is present at any one time or not.

The Trindalls' main observation now, comparing that river system today with the experiences they had as young drovers, is that there is far less water available. They certainly remembered the big floods of the 1950s, and could compare them to the floods in recent times. But overall, Joe says, 'when we used to travel, we knew every hole, and the last time we was there, everything was changed ... where we used to water the big heaps of stock, now you couldn't even water a dog. ${ }^{25}$ Their thoughts about irrigation and the damage it has done to the land around the Namoi where

24 Pearly and Joe Trindall, interview by Phil Duncan (the Trindalls' nephew) and Heather Goodall, with Jodi Frawley and Scott Nichols, 6 September 2010.

25 Pearly and Joe Trindall, interview. 
they lived in their old age have been recorded elsewhere. ${ }^{26}$ Their experiences are recounted here to highlight their overall knowledge of the river system as a floodplain. This knowledge extends beyond any one channel or river. It can be drawn on to understand more about the riverine habitat for fish in any of the reaches across this complex system, rather than on one reach alone.

\section{Storying rivers}

These are all ways that the work that rivers do and the work that people do is entangled. There is a further way we can consider rivers to work that arises from the variability of Australian rivers-the 'freshes' that flow down the rivers from rain in any one of many tributaries. The 'fresh' can come at any time. The river might rise in a 'fresh' because it has rained a thousand kilometres away, or it might be raining just upstream. It is these 'freshes' that are obstructed or ended altogether by the 'regulation' caused by weirs and dams. Yet, not only are the living things in the river adapted to this variability, but also the changing level of waters offers even more for those Aboriginal people who know the stories of the river.

The upper Darling is a floodplain and so it may not be surprising that the big narratives of the philosophy or law of the Aboriginal people who have been living along the river for millennia - the Kamilaraay, Yuwalaraay, Murawarri, Wailwan and Ngiyampaa - all give a key role to water and its flow through the rivers, their networks and across the land. ${ }^{27}$ Each of these cultural groups—and those along the Murray River-attribute the enormous work of river creation to legendary aquatic creatures, often ancestral figures to humans as well as today's more-than-human creatures, in conflicts and interactions with each other. The centrality of water in any form is common in many Aboriginal cultural narratives, even those of the Central Australian desert country. ${ }^{28}$

In those of the upper Darling, the water itself has a storytelling role. The agency of the water, embodied as the 'fresh', allows stories to come to human awareness. Tex Skuthorpe, a Yuwaliyaay artist and river activist, has explained a story from his community on the northern tributaries of the upper Darling, in which a key character is an ancestral woman who only becomes visible as the water flows over the rocky bed when the river has risen to a certain level. I have written elsewhere about the work Tex himself has done through his art, in allowing Anglo-Australians

\footnotetext{
26 Jodi Frawley, Scott Nichols, Heather Goodall and Liz Baker, Namoi: Talking Fish: Making Connections with the rivers of the Murray Darling Basin (Canberra: Murray Darling Basin Authority, 2011), www.dpi.nsw.gov.au/_data/ assets/pdf_file/0004/634216/Namoi_FINAL-Jan-2013-for-web.pdf, accessed 30 October 2017.

27 Frawley et al., Talking Fish.

28 Fred R. Myers, Pintubi Country, Pintubi Self: Sentiment, place and politics among Western Desert Aborigines (Berkeley, CA: University of California Press, 1991); Deborah Bird Rose, Dingo Makes Us Human: Life and Land in an Australian Aboriginal Culture (Melbourne: Cambridge University Press, 1992).
} 
like myself a different way to see the rivers and their flow across his country. Here is what I wrote about his explanation of the work of the river itself in making the story visible:

'The water shows us the country' is a phrase Tex repeats often in his explanation of his painting, stressing the need to see not just one but many floods to gain a deep understanding of the land beyond the river banks. So the water not only creates the land of the floodplain, it makes it visible. But more than the shape of the country, the flow is important for the meanings it reveals. Tex explains that an important site in his country is a series of rocks within a river bed. Only when the level of the river reaches a certain depth does the water flowing over the rocks make the shape of the ancestral being whose spirit is embodied within the rock, allowing the story not only to be told but to be seen. Again, Tex repeats, 'the water shows us'. ${ }^{29}$

The water and the flow embody and conserve, care for and nurture the stories. Without the freshes, the stories may remain in human memory, but they cannot be seen. It is the work the river does that brings the stories into view.

Exploring the concept of work allows us to see conflicts between the many interactions that people have with these inland rivers. Some of the work expectations and demands-like that of the technology of pumps and dams - denigrate or interfere with other expectations about the work the rivers should be doing, such as nurturing fish and other living beings and fostering conditions for sharing stories, or even telling the stories themselves. These are very real and pressing conflicts for the human populations that live along the river, and indeed for all Australians. The consequences for the more-than-human world of the rivers are even more dramatic. This accounting of conflicts goes far beyond the debates that have filled the pages of newspapers over some years now as the Murray-Darling Basin Authority tries to arbitrate between the many conflicted views about what a river should do, now and in the future. Recognising the many dimensions to these conflictsrealising that they are far broader than megalitres, 'buy-backs' and 'environmental flows'-may allow a discussion that is more fruitful than the shrill calls to maintain profits that have been issuing relentlessly from the commercial quarter. 
This text is taken from International Review of Environmental History, Volume 4, Issue 1, 2018, edited by James Beattie, published 2018 by ANU Press, The Australian National University, Canberra, Australia.

doi.org/10.22459/IREH.04.01.2018.08 